OPEN ACCESS

Edited by:

Giovanni Stefano,

Michigan State University,

United States

Reviewed by:

Jose Antonio Monreal,

University of Seville, Spain

Suriyan Cha-um,

National Science and Technology

Development Agency, Thailand

*Correspondence:

Na Sui

suina800101@163.com

${ }^{\dagger}$ These authors have contributed equally to this work

Specialty section:

This article was submitted to Plant Abiotic Stress,

a section of the journal

Frontiers in Plant Science

Received: 07 August 2019 Accepted: 09 December 2019

Published: 15 January 2020

Citation:

Yang Z, Li J-L, Liu L-N, Xie Q and Sui N (2020) Photosynthetic Regulation Under Salt Stress and Salt-Tolerance Mechanism of Sweet Sorghum.

Front. Plant Sci. 10:1722. doi: 10.3389/fp/s.2019.01722

\section{Photosynthetic Regulation Under Salt Stress and Salt-Tolerance Mechanism of Sweet Sorghum}

\author{
Zhen Yang ${ }^{1,2+}$, Jin-Lu Li ${ }^{1 \dagger}$, Lu-Ning Liu ${ }^{3,4}$, Qi Xie ${ }^{5}$ and Na Sui ${ }^{1 *}$ \\ 1 Shandong Provincial Key Laboratory of Plant Stress, College of Life Sciences, Shandong Normal University, Jinan, China, \\ 2 Shandong Provincial Key Laboratory of Microbial Engineering, School of Biological Engineering, Qilu University of \\ Technology (Shandong Academy of Sciences), Jinan, China, ${ }^{3}$ Institute of Integrative Biology, University of Liverpool, \\ Liverpool, United Kingdom, ${ }^{4}$ College of Marine Life Sciences, Ocean University of China, Qingdao, China, 5 State Key \\ Laboratory of Plant Genomics, Institute of Genetics and Developmental Biology, The Innovative Academy of Seed Design, \\ China University of Chinese Academy of Sciences, Beijing, China
}

Sweet sorghum is a C4 crop with the characteristic of fast-growth and high-yields. It is a good source for food, feed, fiber, and fuel. On saline land, sweet sorghum can not only survive, but increase its sugar content. Therefore, it is regarded as a potential source for identifying salt-related genes. Here, we review the physiological and biochemical responses of sweet sorghum to salt stress, such as photosynthesis, sucrose synthesis, hormonal regulation, and ion homeostasis, as well as their potential salt-resistance mechanisms. The major advantages of salt-tolerant sweet sorghum include: 1) improving the $\mathrm{Na}^{+}$exclusion ability to maintain ion homeostasis in roots under saltstress conditions, which ensures a relatively low $\mathrm{Na}^{+}$concentration in shoots; 2) maintaining a high sugar content in shoots under salt-stress conditions, by protecting the structures of photosystems, enhancing photosynthetic performance and sucrose synthetase activity, as well as inhibiting sucrose degradation. To study the regulatory mechanism of such genes will provide opportunities for increasing the salt tolerance of sweet sorghum by breeding and genetic engineering.

Keywords: sweet sorghum, salt-tolerance mechanism, $\mathrm{Na}^{+}$exclusion, photosynthesis, sugar content

\section{INTRODUCTION}

Soil salinization is a compelling environmental problem worldwide (Landi et al., 2017). Over $\sim 6 \%$ of the world's lands are saline and $20 \%$ of irrigated lands are currently salt-affected (Song and Wang, 2015; Yuan et al., 2016a). Salt stress is an important factor determining plant growth and yields (Mahajan and Tuteja, 2005; Deng et al., 2015), by substantially affecting key biological processes, such as photosynthesis (Feng et al., 2014), energy metabolism (Song et al., 2016), protein synthesis, and lipid metabolism (Sui et al., 2010; Sui and Han, 2014; Sui et al., 2018). A limited number of crops can survive in saline land, which can lead to desertification (Flowers and Colmer, 2010). Another two limiting factors for the development of the economy in many developing countries are the shortage of cultivated land and energy crisis (IEA, 2019). At present, these developing countries are facing the problem of "large population and less land". As a consequence, the development of biomass energy and feed crops is restricted by the reduction of cultivated land resources. If energy 
crops and feed crops with high salt tolerance can be widely planted on saline soils, it is of strategical importance to provide solutions for addressing the challenges of energy and food security.

Plants have evolved various adaptive mechanisms in response to salt stress, leading to survival in saline land. These mechanisms occur at multiple levels, the molecular level (Yuan et al., 2016b) and the physiological and biochemical levels (Guo et al., 2012; Kong et al., 2016; Leng et al., 2018). At the molecular level, many genes related to salt-stress responses are differentially expressed after plants sense the external salt-stress signals (Zhu, 2001). For example, OsCCC1 plays a significant role in $\mathrm{K}+$ and $\mathrm{Cl}-$ homeostasis (Kong et al., 2011), overexpression of SsHKT1;1 (Shao et al., 2014), AtZFP1 (Han et al., 2014), SsCHLAPXs (Pang et al., 2011), and PcAPX (Cao et al., 2017) enhances plant salt tolerance. The differential expressions of these genes then drive the salt-stress responses at the physiological and biochemical levels (Cui et al., 2018). The first step is to block $\mathrm{Na}^{+}$transport to shoots through apoplastic barriers, including Casparian bands and suberin lamellae (Krishnamurthy et al., 2011). The second step is to dilute $\mathrm{Na}^{+}$in the cytoplasm through $\mathrm{Na}^{+}$compartmentalization by transporting $\mathrm{Na}^{+}$into the vacuole (Blumwald, 2000). The third step is to exclude $\mathrm{Na}^{+}$outside using a $\mathrm{Na}^{+} / \mathrm{H}^{+}$antiporter in the plasma membrane. The transport of $\mathrm{Na}^{+}$from roots to leaves can also be restricted by a high-affinity $\mathrm{K}^{+}$transporter (HKT) (Byrt et al., 2007; Byrt et al., 2014).

Sweet sorghum [Sorghum bicolor (L.) Moench], which was generated from grain sorghum, has been widely cultivated for animal feed production in tropical and subtropical regions and, in particular, has a large planting area in Asia, Africa, and many developing countries (Antonopoulou et al., 2008). India is the largest sorghum grower in the world, with 7.5 million hectares of lands for growing sweet sorghum, followed by Nigeria (7.6 million hectares) and Sudan (6.6 million hectares) (Rao et al., 2013). In America, about 2.6 million hectares were devoted to sorghum for grain and 153,780 hectares were used for sorghum silage (Getachew et al., 2016). In China, about 100,000 hectares of lands were used to plant sweet sorghum. Sweet sorghum has the characteristics of high photosynthetic efficiency (Guo et al., 2018a), high fermentable sugar content in stalks, and high salt tolerance (Vasilakoglou et al., 2011; Sui et al., 2015). As a C4 crop, it has the ability to produce high biomass under stress conditions. Its high nitrogen-use efficiency enables it to produce two to three times more biomass per harvest than the more commonly used silage crop such as maize (Xie and Xu, 2019). Compared with the original feed crops, sweet sorghum presents the advantages of possessing high temperature and drought tolerance levels, high yields, low soil fertility requirements, and good palatability and digestibility (Chen L. et al., 2018). It has been reported that the protein content in sweet sorghum leaves is up to $22 \%$ (Ferraris and Charles-Edwards, 1986). A metaanalysis of feeding experiments found that cows fed with sweet sorghum silage could produce more milk ( $1.64 \mathrm{~kg} / \mathrm{day} / \mathrm{cow})$ with an improved quality compared with those fed with maize silage (Sánchez-Duarte et al., 2018). Additionally, most sorghum accumulates high amounts of tannins in the seeds. It has been shown that tannins can promote milk production, lambing percentage, and growth of wool, as well as reducing the risk of rumen bloat (Patra and Saxena, 2011). In an in vitro experiment, the supplement of $15 \mathrm{mg}$ tannins in $500 \mathrm{mg}$ of total oven-dried guinea grass reduced methane $(\mathrm{CH} 4)$ production by $47 \%$ (Tan et al., 2011). These findings imply another important advantage of using sweet sorghum silage over other crops: lower methane production and lower damage to the atmosphere. Salt-tolerant sweet sorghum species have stable or increased Brix scores in their stems under salt-stress conditions (Sui et al., 2015). However, salt-sensitive sweet sorghum species often exhibit the decreased net photosynthetic rates and comprehensive utilization degrees of Brix. Salt resistance of sweet sorghum can be improved by the pivotal process of salt exclusion, which induces the accumulation of $\mathrm{Na}^{+}$in the vacuoles of root parenchymata and limits $\mathrm{Na}^{+}$transportation into shoots (Yang et al., 2018).

This review will focus on the physiological and biochemical responses of sweet sorghum to salt stress and the salt-tolerance mechanisms, and discuss how this crop plant can be used to improve saline land.

\section{PHYSIOLOGICAL AND BIOCHEMICAL RESPONSES OF METABOLIC PROCESSES TO SALT STRESS}

Many important metabolic processes are affected by salt stress at the physiological and biochemical levels. Generally, photosynthesis and growth rate of most plants would be inhibited by salt stress. The regulation of these metabolic processes in response to salt stress could modulate the ability of salt tolerance among sweet sorghum accessions.

\section{Photosynthesis}

Photosynthesis is the most important process occurs in the chloroplasts of higher plants. Solar energy can be converted into chemical energy by plants through photosynthesis. Photosynthesis includes light and dark reactions, each of which consists of a series of redox reactions related to energy capture and conversion (Liu, 2016). At the initial step of photosynthesis, light energy is captured by the peripheral light-harvesting complexes, which contain most of the chlorophyll and carotenoid pigments and are peripherally associated with photosystems (PSs) I and II (Figure 1A) (Galka et al., 2012). For many plants such as tomato, Zygophyllum xanthoxylum, and Phaseolus vulgaris, salt stress could affect the chloroplast structures and decrease the chlorophyll content resulting in the reduced photosynthetic rate (Sudhir and Murthy, 2004; Wydrzynski, 2008; Ma et al., 2012).

The decrease in photosynthesis induced by salt stress could be relevant to the stomatal and/or nonstomatal factors in soybean seedlings (Jiao et al., 2017). Salt stress has direct and indirect effects on the chlorophyll content and photosynthetic efficiency of plants. The direct effects are achieved by regulating the activity and expression levels of enzymes involved in chlorophyll 
A
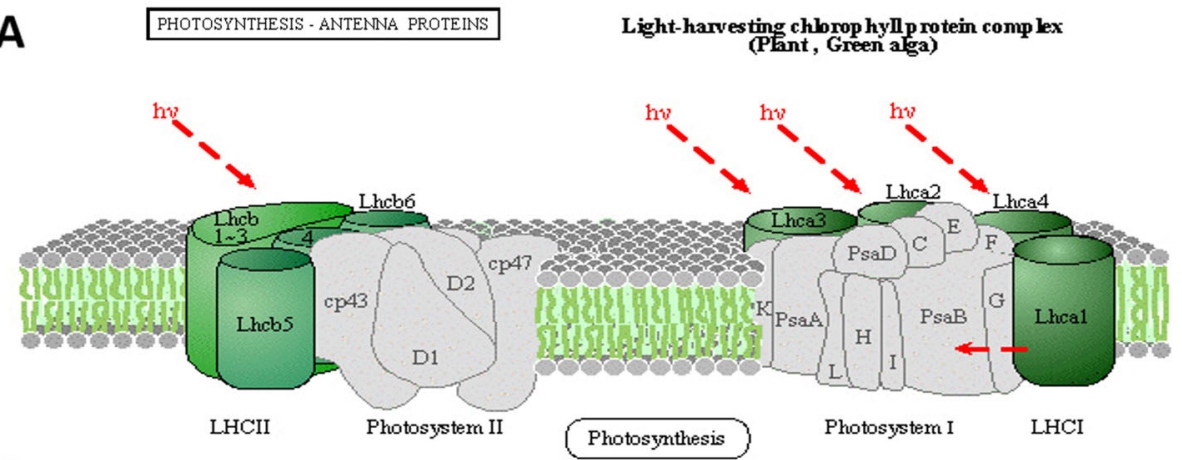

B
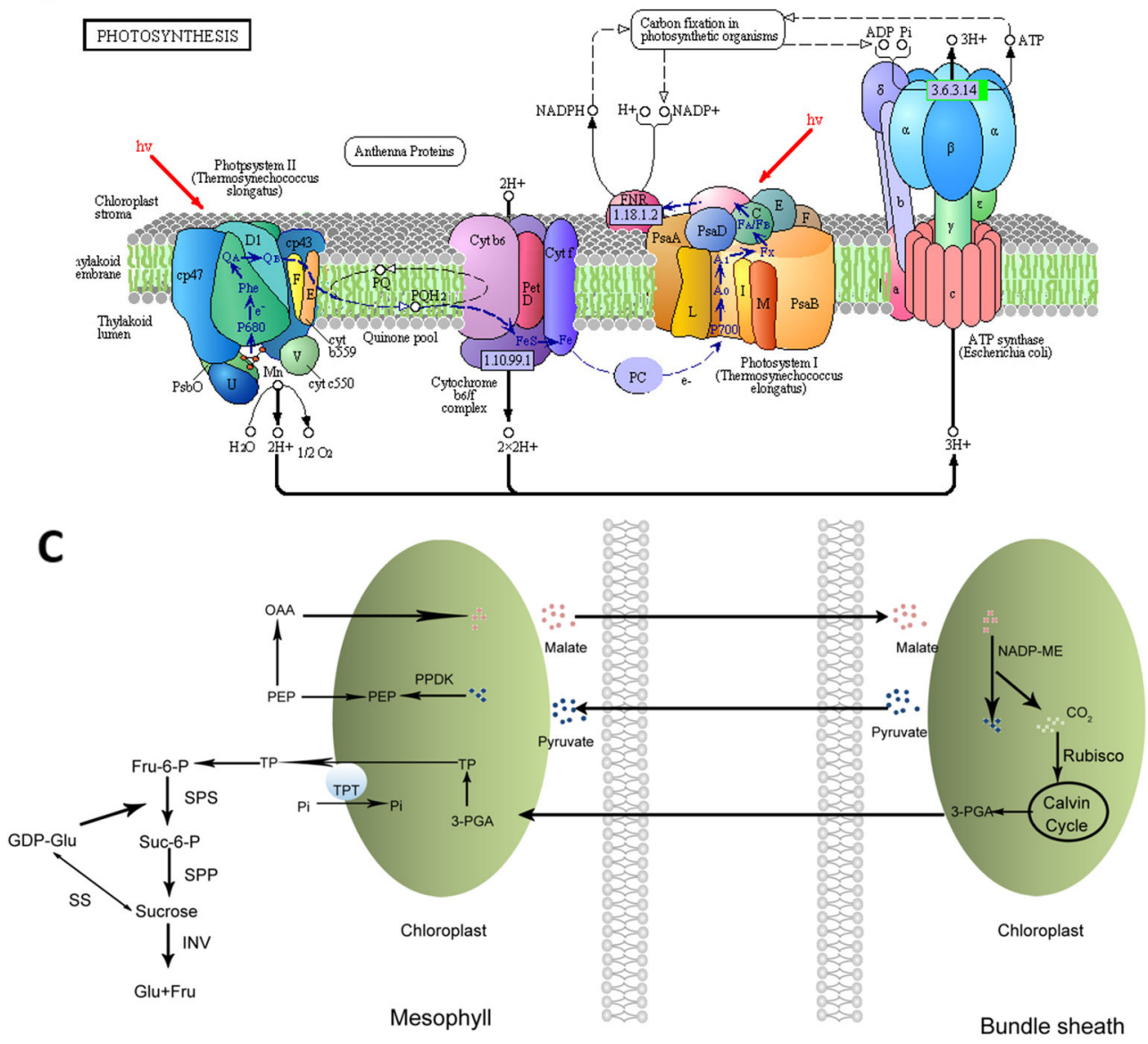

FIGURE 1 | Visualization of pathways related to the accumulation of sucrose in sweet sorghum under salt stress (Repaint refers to Sui et al., 2015).

(A): Photosynthetic antenna systems and the light-harvesting process; (B): photosynthetic pathway (Sui et al., 2015); (C): pathway of the carbon fixation in photosynthetic organisms and sucrose biosynthesis.

biosynthesis and photosynthesis (Figure 1B). The indirect effects are achieved by specific regulating pathways such as antioxidant enzyme systems. It has been reported that the maximum quantum yield of photosystem II (PSII; $\mathrm{F}_{\mathrm{v}} / \mathrm{F}_{\mathrm{m}}$ ), photochemical quenching coefficient $(\mathrm{qP})$, and electron transport rate (ETR) substantially decreased, whereas non-photochemical quenching
(qN) increased in sorghum under saline conditions (Netondo et al., 2004). In poplar (Populus spp.), salt stress could inhibit $\mathrm{F}_{\mathrm{v}} /$ $\mathrm{F}_{\mathrm{m}}$ due to the salt-induced increase of the minimal fluorescence $\left(\mathrm{F}_{\mathrm{o}}\right)$ and the notable decline of the maximal fluorescence $\left(\mathrm{F}_{\mathrm{m}}\right)$. It could also result in the decrease of $\mathrm{qP}$ but could greatly elevate the coefficient of nonphotochemical $\mathrm{qN}$ in the light-adapted state 
(Wang et al., 2007). In contrast, $\mathrm{F}_{\mathrm{v}} / \mathrm{F}_{\mathrm{m}}$ was almost not affected by salt stress in rice, whereas $\mathrm{qN}$ increased in sensitive cultivars with the increasing salt stress (Dionisio-Sese and Tobita, 2000).

It was also reported that salt stress can affect water potential, stomatal conductance, and sugar accumulation to induce inhibition and ion toxicity (Feng et al., 2014). In salt-sensitive sweet sorghum, salt stress was revealed to significantly decrease the net photosynthetic rate, PSII photochemical efficiency, stomatal conductance, and intercellular $\mathrm{CO}_{2}$ concentration (Sui et al., 2015). In contrast, salt-tolerant sweet sorghum genotypes can still exploit certain mechanisms to minimize these responses throuth apoplastic barriers (Figure 2B). The mechanism of salttolerant sweet sorghum for maintaining high photosynthetic efficiency under salt stress may be related to the contributions of several pathways, such as maintaining the stability of the photosynthetic system and enhancing the efficiency of $\mathrm{CO}_{2}$ fixation. In the salt-tolerance and salt-sensitive genotypes, $\mathrm{F}_{\mathrm{v}} /$ $\mathrm{F}_{\mathrm{m}}$ and the actual PSII efficiency $\left(\Phi_{\mathrm{PSII}}\right)$ were reduced with increasing $\mathrm{NaCl}$ concentration, and the decrease was more significant in Roma which is sensitive to salt stress. The chlorophyll content in M-81E sweet sorghum was not altered greatly by $50 \mathrm{mM} \mathrm{NaCl}$, whereas it decreased in Roma (Sui et al., 2015). No significant changes in the photosynthetic rate, stomatal conductance, and intercellular $\mathrm{CO}_{2}$ concentration were observed in M-81E under salt stress. However, these photosynthesis-related indicators in Roma were significantly influenced by salt stress. Additionally, many genes mapped to the photosynthesis pathway showed different expressions in Roma and all of them were down-regulated under salt stress (Sui et al., 2015). Most of these genes are related to the photosystem complexes, the connection between photosystems and light-harvesting proteins, and electron transport chain. Only a few genes in M-81E mapped to the photosynthesis pathway were affected by salt stress, and 2 genes related to the stable assembly of the oxygen-evolving complex and ATP synthase were up-regulated under salt stress (Sui et al., 2015). These results suggest that salt stress could affect the assembly of photosystems and reduce the efficiency of electron transport, resulting in the decrease of ATP and NADPH in plants under salt stress. These effects are particularly critical in salt-sensitive species, whereas salt-tolerant species can protect the formation of photosynthetic assemblies by increasing the expression of particular genes.

Sweet sorghum possesses the C4 pathway of carbon fixation. $\mathrm{CO}_{2}$ is fixed initially in the mesophyll cells by phosphoenolpyruvate carboxylase (PEPC) to form malic acid. Malic acid can then diffuse into bundle sheath cells, where they are decarboxylated, and the released $\mathrm{CO}_{2}$ is then fixed by Rubisco (Hatch, 1987), the key enzyme in photosynthetic $\mathrm{CO}_{2}$ assimilation (Whitney et al., 2011). The phosphorylation of PEPC depends on the interplay of phosphoenolpyruvate carboxylase kinase (PEPC-k) and a $2 \mathrm{~A}$-type protein phosphatase (Carter et al., 1990; Vidal and Chollet, 1997). It has been reported that the PEPC-k content in leaves of sorghum

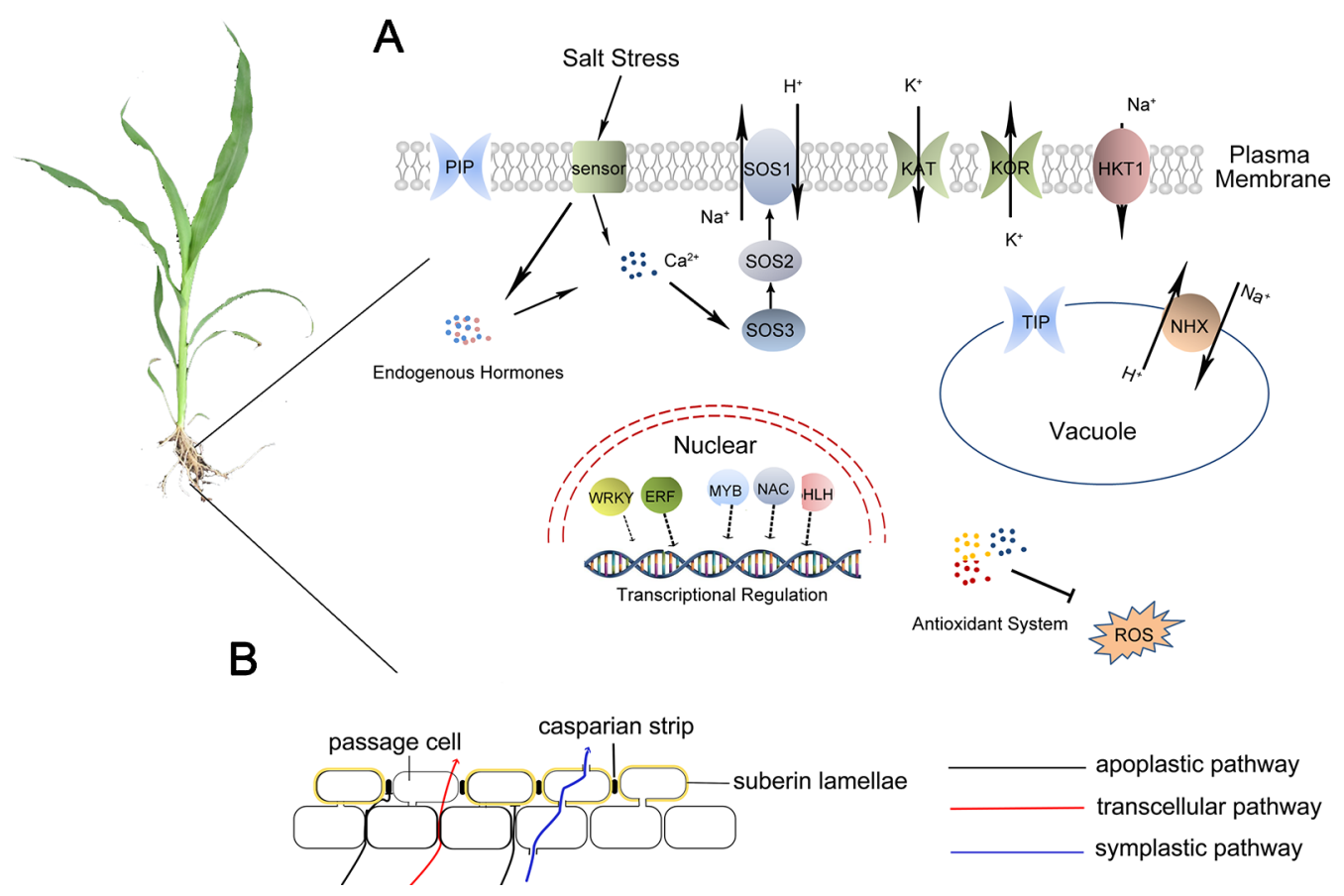

FIGURE 2 | Possible roles of salt resistance in sweet sorghum. (A): Cells of sweet sorghum firstly sense Na+ by an unknown sensor and change the content of intracellular hormones and $\mathrm{Ca}^{2+}$. The expression of some transcription factors, such as NAC, bHLH, MYB, is also initiated. These transcription factors then activate the expression of genes encoding proteins related to salt stress response such as SOS1, HKT1, NHX, ROS scavenging proteins, aquaporins, and some ion channels. (B): Physical barrier effect of root apoplastic barriers can block the apoplastic transpiration bypass flow of water and solutes. 
could be induced by salt stress under both light and dark conditions, which contributes to the improvement of carbon fixation efficiency (Echevaria et al., 2001; García-Mauriño et al., 2003). NADP-Malate dehydrogenase (NADP-ME) is a critical enzyme of the $\mathrm{C} 4$ pathway, which catalyzes the oxidative decarboxylation of malic acid to provide $\mathrm{CO}_{2}$ to Rubisco. It has been shown that the expression of the gene encoding NADPME could be activated by salt stress (Sun et al., 2003; Liu et al., 2007). Recently, it has been revealed that NADP-ME in sweet sorghum is associated with salt tolerance. NADP-ME in M-81E sweet sorghum was activated by salt stress and overexpression of SbNADP-ME increased the photosynthetic capacity in Arabidopsis under salt stress (Guo et al., 2018b). The increase of NADP-ME may lead to an increase of $\mathrm{CO}_{2}$ and pyruvate levels, which enhanced the $\mathrm{CO}_{2}$ fixation efficiency. Additionally, $\mathrm{NADPH}$ can also participate in the reactive oxygen species (ROS) metabolism by providing power (Mittler, 2002). Møller reported that the NADPH-specific glutathione reductase (GR) can use NADPH to catalyze glutathione reduction for scavenging ROS (Møller, 2001).

\section{Sucrose Synthesis, Metabolism, and Transportation}

Sweet sorghum represents an excellent model for fermentative production due to the fact that its stem contains rich fermentable sugars, such as sucrose, fructose, and glucose (Almodares and Hadi, 2009). Sucrose is the main sugar accumulated through photosynthesis, accounting for $\sim 85 \%$ of the total content, in the stems of sweet sorghum (Gnansounou et al., 2005; Kühn and Grof, 2010). The flow direction of triose phosphate formed during photosynthesis determines the distribution of photosynthetic products. It remains in the chloroplast stroma for the completion of the Calvin cycle or to be converted to starch or enters the cytoplasm via triose phosphate translocator and synthesizes sucrose under the action of a series of enzymes, such as sucrose phosphate synthetase (SPS), sucrose synthetase (SS), and invertase (INV). Sucrose is temporarily stored in the vacuoles or is exported using long-distance transport through the phloem (Figure 1C).

Plant organs are generally divided into the source and sink organs (Turgeon, 1989). A source organ possessing photosynthetic activities usually has a net output of light assimilation, which occurs in the mature leaf. Sucrose is the main source of carbon and energy in the epidermal tissue of plants. It is synthesized in the cytoplasm of leaves (source tissues) where it is loaded into the phloem and is transported to sink tissues (Guimaraes et al., 1997; Mccormick et al., 2010). Sucrose can be transported from the phloem to sink tissues through two pathways (Qazi et al., 2012). In sugarcane, the radial transfer of sucrose from the vascular bundles to parenchymal cells of the sucrose-storing internodes follows a symplastic pathway (Rae et al., 2005). While, in sorghum, it follows an apoplastic pathway (Tarpley and Vietor, 2007). Additionally, sucrose transporters (SUTs) are involved in the long-distance transport of sucrose through the phloem, fulfilling the loading and unloading functions. Among these SUTs, SUT1 is highly specific for sucrose transport in monocotyledonous plants (Scofield et al.,
2007; Reinders et al., 2010; Slewinski and Robert and Braun, 2010). The expression of SUT1 in the internodes of sweet sorghum was lower than that in grain sorghum, which may reflect the reduced retrieval of sucrose in the phloem and consequently, an enhanced efflux into storage parenchymal cells (Qazi et al., 2012).

Many enzymes, such as SPS, SS, and INV, are tightly involved in sugar metabolism (Turgeon, 1989). SS can catalyze both the synthesis and the decomposition of sucrose (Schäfer et al., 2005; Hoffmann-Thoma et al., 2010). SPS takes part in the synthesis of sucrose phosphate, which can be converted into sucrose by the catalysis of sucrose phosphate phosphatase (Lunn and Macrae, 2003). INV plays a key role in the process of sucrose degradation and mainly catalyzes the decomposition of sucrose to monosaccharides (Lunn and Macrae, 2003).

\section{Hormones}

Hormones play essential roles in the germination, growth, and development of plants (Chen et al., 2013a; Li et al., 2015). Hormones and their signaling pathways are integrated to allow the triggering of appropriate cellular and physiological responses to adapt to stress circumstances (Ryu and Cho, 2015). To cope with abiotic stresses, several plant hormones regulate defense response reactions (Kazuo et al., 2009; Ahmad and Prasad, 2012). Plant hormones play important roles in responses to salt stress (Javid et al., 2011; Zeng et al., 2018). At the physiological and biochemical levels, sweet sorghum triggers an endogenous hormone-related signaling cascade after sensing external salt stress, which provokes downstream salt-stress responses. Under salt-stress conditions, sweet sorghum can restrict the transport of $\mathrm{Na}^{+}$to the aboveground plant parts by salt exclusion and enhance the antioxidant system simultaneously, and resist the secondary oxidative stress caused by salt stress (Sui et al., 2015; Yang et al, 2018). These protective mechanisms allow sweet sorghum to maintain high photosynthetic efficiency under salt-stress conditions. Maintenance of high photosynthetic performance, up-regulation of genes functioning in sucrose synthesis (SPS and SS encoding genes), and down-regulation of genes related to sucrose degradation (INV-encoding genes) triggered by salt stress lead to the accumulation of sucrose of salt-tolerant sweet sorghum lines.

Among the known hormones, abscisic acid (ABA), jasmonate (JA), ethylene, and cytokinin (CK) have been demonstrated to mediate plant defense responses against abiotic stresses (Nakashima and Yamaguchishinozaki, 2013). One of the fastest responses to abiotic stress is the accumulation of $\mathrm{ABA}$, which is a key regulator in the activation of plant cellular adaptation to drought and salt stresses (Chen et al., 2013b). The increased levels of ABA facilitate the binding to its receptor to initiate signal transduction, leading to cellular responses to stresses (Ng et al., 2014; Sah et al., 2016). Additionally, many other salt-stress-related pathways, such as proline accumulation and calcium signaling, are also physiologically linked to the ABA signaling pathway (Yang et al., 2017). CKs play roles in the regulation of plant responses to stress (Ha et al., 2012). Unlike $\mathrm{ABA}, \mathrm{CKs}$ can play positive or negative roles under stress conditions (Zwack and Rashotte, 2015; Yang et al., 2017). 
Colebrook et al. (2014) illustrated that the gibberellin levels affect plant growth under several stress conditions. Although hormones are critical in the salt-stress responses of sweet sorghum, the key hormones functioning in the response reactions vary among sweet sorghum genotypes and possess distinct levels of salt tolerance. Yang et al. (2017) reported that in the salt-tolerant inbred line M-81E, ABA may play a key role in the salt-stress response. However, in salt-sensitive inbred lines, JA may act as the key regulatory hormone of salt stress. It is presumably that $\mathrm{ABA}$ and $\mathrm{JA}$ regulate the growth and development of sweet sorghum in different tissues of sweet sorghum. ABA plays roles in predominantly leaves whereas JA is active mainly in roots (Yang et al., 2017). It has been described that ABA modulates the degradation of PEPC- $\mathrm{k}$ in sorghum leaves by increasing kinase activity in the illuminated leaf of the non-stressed plant and decreasing PEPC-k activity in the dark (Monreal et al., 2007). These results indicated that the changes of ABA content in the leaves of salt-tolerant sweet sorghum variants may be related to the maintenance of high photosynthetic efficiency of sweet sorghum under salt stress.

\section{Maintenance of Ion Homeostasis}

Under salt stress, sorghum can operate osmotic regulation by transporting ions into vacuoles or accumulating soluble substances (Lacerda et al., 2003). Sweet sorghum can scavenge ROS through enzymatic and non-enzymatic antioxidant systems, adapting to secondary oxidative stress caused by salt stress (Chai et al., 2010). In addition, sweet sorghum can also accumulate $\mathrm{Na}^{+}$in roots and limit the transportation of $\mathrm{Na}^{+}$up to shoots under salt stress, which is called salt exclusion (Dai et al., 2014), an important salt-tolerance-related process in monocotyledonous crops, including rice, maize, and sweet sorghum. Plants having the characteristics of salt exclusion can accumulate $\mathrm{Na}^{+}$in the vacuoles of root parenchyma and suppress $\mathrm{Na}^{+}$transportation into shoots. Root apoplastic barriers consist of Casparian bands and suberin lamellae. The formation of apoplastic barriers can block the apoplastic transpirational bypass flow of $\mathrm{Na}^{+}$(Krishnamurthy $\mathrm{P}$ et al., 2009; Yang et al., 2018) (Figure 2). Additionally, the highaffinity potassium transporter (HKT) plays important roles in retrieving $\mathrm{Na}^{+}$transport from roots to shoots. Salt stress induces the expression of SbHKT1;4 in salt-tolerant inbred sorghum, and it is vital for balancing the ratio of $\mathrm{Na}^{+} / \mathrm{K}^{+}$to improve plant growth (Wang et al., 2014). The combining effects of apoplastic barriers in roots and $\mathrm{Na}^{+}$transport by HKTs lead to $\mathrm{Na}^{+}$ accumulation in roots. The accumulated $\mathrm{Na}^{+}$is finally transported into the vacuoles through NHXs or out of root cells by the $\mathrm{Na}^{+} / \mathrm{H}^{+}$antiporters in the plasma membrane (Yang et al., 2018) (Figure 2A).

\section{ROS Scavenging}

In plants, dynamic balance of the ROS content is essential for plant growth. However, when the ROS accumulation exceeds the tolerance of the cell, it will cause damage to plants by attacking membrane structure or mediating apoptosis (Xue et al., 2013). Salt stress can induce the accumulation of ROS, which could greatly affect plant photosynthesis, metabolism, signal transduction, and other physiological and biochemical processes. The antioxidant system is adopted in plants to scavenge ROS and free radicals to prevent damages caused by ROS (Sui et al., 2015). Antioxidant enzymes serve as important components of the antioxidant system to remove ROS in plants and increase plant resistance, allowing the maintenance of physiological growth and development. For instance, superoxide dismutase is used to scavenge $\mathrm{O}_{2}{ }^{-}$by converting it to $\mathrm{H}_{2} \mathrm{O}_{2}$. Catalase is used to scavenge $\mathrm{H}_{2} \mathrm{O}_{2}$ by catalyzing it to $\mathrm{H}_{2} \mathrm{O}$ and $\mathrm{O}_{2}$ (Mittler, 2002). The expression of ROS-associated antioxidant enzymes is commonly induced by salt stress (Evelin et al., 2009; Xue et al., 2013). Sorghum could use these antioxidant enzymes to adapt to salt and drought stresses (Jogeswar et al., 2006).

\section{Osmotic Stress}

The responses of plants to salt stress are characterized by two phases. The first phase is determined by osmotic stress and the second phase is ionic stress (Munns, 1993). Plants are capable of adjusting their water balance in response to salt stress. Plants adapt to osmotic stress mainly by reducing transpiration and accumulating osmotic adjustment substances (Chen M. et al., 2018). It has been reported that sorghum accumulated proline and soluble carbohydrates after $\mathrm{NaCl}$ treatment for 20 days (Heidari, 2009). The accumulation of these substances reduced the water potential of sorghum and maintained the waterabsorbing capacity under salt stress. The aquaporin proteins play important roles in transportation of water across biological membranes, which is crucial for plants to combat salt stress (Xin et al., 2014). In sweet sorghum, the aquaporin-encoding genes in both salt-tolerant and salt-sensitive lines were up-regulated under salt stress, which may promote water transport efficiency (Yang et al., 2018). Additionally, the stomatal conductance in leaves of sweet sorghum was notably decreased under salt stress, which plays an important role in reducing water loss through transpiration (Sui et al., 2015).

\section{RESPONSES TO SALT STRESS AT DIFFERENT DEVELOPMENTAL STAGES OF SWEET SORGHUM}

Sweet sorghum has high salt tolerance (Vasilakoglou et al., 2011; Sui et al., 2015). However, the salt effects on sweet sorghum vary among species and occur in different developmental stages. Germination is the starting point for the growth and developmental processes for all crops. Therefore, high germination ability is important for crops in saline soils. The inhibition effects of salt stress on plant germination are mainly through two ways. Primarily, salt stress can drastically decrease the osmotic potential of the soil solution to retard water absorption of seeds. Additionally, salt stress can also cause the sodium and/or chloride toxicity to the embryo and alter protein synthesis (Panuccio et al., 2014). Seed germination is a major factor limiting the establishment of plant populations under saline conditions. Salt-tolerant sweet sorghum germplasms can 
maintain a good germination state under salt stress (Almodares et al., 2007; Patanè et al., 2009; Patanè et al., 2013). However, under salt-stress conditions, the germination of salt-sensitive sweet sorghum germplasms is significantly inhibited. The germination rate, germination index, germination energy, and fresh weights of roots and shoots were all decreased under salt stress, which result in low densities and low yields (Ding et al., 2018).

It has been reported that the increase in the $\mathrm{Na}^{+}$ concentration and the decrease in the $\mathrm{K}^{+}$concentration in saltsensitive sweet sorghum germplasms during salt stress could lead to the decreased levels of several synthesis and metabolism actions, such as photosynthesis and nutrient transport (Sui et al., 2015; Yang et al., 2018), impeding the growth of both roots and shoots (Almodares et al., 2014). These effects appear to be more significant in salt-sensitive sweet sorghum inbred (Yang et al., 2018). These implied that tolerance to salt stress in sweet sorghum may be related to the decrease of $\mathrm{Na}^{+}$and $\mathrm{Cl}^{+}$ accumulation and the maintenance of $\mathrm{K}^{+}$level.

Many of the screening experiments on sweet sorghum have been performed under controlled environmental conditions during the early developmental stages, such as germination and seedling stages. The salt tolerance of only a few germplasms under field conditions has been reported (Vasilakoglou et al., 2011; Fan et al., 2013) as the variation in environment (such as alternations in temperature and rainfall) would easily lead to the variation in the growth of sweet sorghum. A study of four sweet sorghum species in Northern Greece has revealed that sorghum grown in intermediate-salt soil $\left(3.2 \mathrm{dS} \mathrm{m} \mathrm{m}^{-1}\right)$ produced more juice and sugar, and have greater crop and ethanol yields than that grown in high-salt soil (6.9 $\mathrm{dS} \mathrm{m}^{-1}$ ) (Vasilakoglou et al., 2011). Moreover, the physiological features of sweet sorghum grown in saline soil vary greatly among germplasms. As it has been reported, some physiological features such as seed emergence rate and growth rate of sweet sorghum decreased under salt stress. However, the plant height, stem width, seed emergence rate, and the total leaf area were significantly higher in salttolerant sweet sorghum germplasm than that in salt-sensitive counterparts (Ding et al., 2013). In addition, photosynthetic parameters and sugar content were also less affected in salttolerant sweet sorghum germplasm than that in salt-sensitive lines (Fan et al., 2013).

\section{RESPONSES OF METABOLIC PROCESSES TO SALT STRESS AT THE MOLECULAR LEVEL}

The responses of metabolic processes to salt stress at the physiological and biochemical levels are closely related to the regulatory expression of some encoding genes. Nowadays, many genes related to salt response in sweet sorghum have been identified and characterized (Buchanan et al., 2005; Sun et al., 2016; Casto et al., 2018). ABA is a key regulator of the activation of plant cellular adaptation to drought and salt stresses. Examination of the differential gene expression in Sorghum after exposure of seedlings to high salinity, osmotic stress, and ABA revealed that 89 genes were induced with onefold changes bigger than 2 in shoots, and 84 genes were induced with two-fold changes in roots by salt and ABA treatments (Buchanan et al., 2005). Moreover, there is a great overlap in gene expression in response to salt and ABA treatments, which indicated that $\mathrm{ABA}$ signaling pathway plays an important role in sorghum in response to salt stress. It has been reported that salt stress can regulate the accumulation of endogenous ABA in sorghum and SbABI5 expression in sorghum roots is a key step in the ABA signaling pathway to improve salt tolerance (Sun et al., 2016). Under salt stress, the ABA synthesis-related gene $S 604 g 030640$ was up-regulated in the leaves of salt-tolerant sweet sorghum inbred lines and was down-regulated in saltsensitive inbred lines. However, genes related to $\mathrm{ABA}$ metabolism showed the opposite trends in the two inbred lines. Additionally, genes related to the ABA signaling pathway, such as $P Y R / P Y L$ and $P P 2 C$, also possess different expression patterns. After treatment with $\mathrm{NaCl}$, the PYL8encoding gene $S 609 g 006700$ was down-regulated in the roots of salt-sensitive Roma. By contrast, the DEGs-encoding gene PP2C was up-regulated in salt-sensitive Roma but was downregulated in salt-tolerant M-81E (Yang et al., 2017). Genes involved in the synthesis, metabolism, and signal transduction of JA, indole-3-acetic acid, and CK in sweet sorghum were also expressed with various regulatory patterns under salt-stress conditions (Yang et al., 2017).

Root apoplastic barriers, consisting of Casparian bands and suberin lamellae, play pivotal roles in blocking the apoplastic bypass flow of water and ions into the stele and $\mathrm{Na}^{+}$transport into shoots (Pignocchi and Foyer, 2003). Salt stress induces the strengthening of the root apoplastic barriers (Krishnamurthy $\mathrm{P}$ et al., 2009). The expression of genes related to apoplastic barriers in sweet sorghum was up-regulated under high salinity conditions (Yang et al., 2018), suggesting that the apoplastic barriers may take part in the salt response of sweet sorghum. HKTs have been proven taking part in retrieving $\mathrm{Na}^{+}$from the xylem vessels thus restricting the transport of $\mathrm{Na}^{+}$from roots to leaves. They are involved in the regulation of $\mathrm{Na}^{+}$and $\mathrm{K}^{+}$ transportation and maintenance of $\mathrm{Na}^{+} / \mathrm{K}^{+}$balance (Byrt et al., 2014). It has been reported that the expression of $S b H K T 1 ; 4$ was strongly up-regulated in salt-tolerant sorghum, correlating with an optimal balanced $\mathrm{Na}^{+} / \mathrm{K}^{+}$ratio and enhanced plant growth (Wang et al., 2014). In sweet sorghum, the expression of SbHKT1;5 was enhanced both in salt-tolerant and salt-sensitive inbred lines after $\mathrm{NaCl}$ treatments, and $S b H K T 1 ; 5$ has a greater expression in the salt-tolerant M-81E (Yang et al., 2018).

In addition, the genes related to ROS scavenging, heat shock proteins, and osmoregulation solutes also showed differential expression in sweet sorghum under $\mathrm{NaCl}$ treatment (Yang et al., 2018). With the expression of these genes, the contents of proline, soluble protein, catalase, and peroxidase increased in sweet sorghum under $\mathrm{NaCl}$ treatment (Oliveira et al., 2011; Ngara et al., 2012). These accumulations may contribute to the increase of salt-resistance capability of sweet sorghum. 
Under salt stress, the genes encoding photosynthetic proteins were also shown to present different expression regulations in distinct sweet sorghum genotypes. The genes encoding Lhcal and Lhcb1-5 were down-regulated in both salt-tolerant and saltsensitive sweet sorghum lines under salt stress (Sui et al., 2015). The expression levels of the genes encoding Lcha2-4 and Lchb6 dropped in salt-sensitive Roma under salt stress but did not change in salt-tolerant M-81E. Moreover, the genes Sb02g002830 and $S b 09 g 021810$ that are related to the stable assembly of the oxygen-evolving complex and ATP synthase were up-regulated, affecting the stability of the photosynthetic apparatus under saltstress conditions (Sui et al., 2015). As a C4 plant, sweet sorghum uses NADP-malic enzyme, ribulose-bisphosphate carboxylase, phosphoenolpyruvate carboxylase, and pyruvate orthophosphate dikinase as the key enzymes in the dark reaction of photosynthesis. When treated with $\mathrm{NaCl}$, the genes encoding these enzymes in sweet sorghum were down-regulated, indicating that salt stress reduced $\mathrm{CO}_{2}$ assimilation. However, genes encoding other enzymes involved in carbon fixation in photosynthetic organisms, such as $\mathrm{NADP}^{+}$-malate dehydrogenase, were extremely enhanced by salt stress in only salt-tolerant sweet sorghum genotypes. This could increase the levels of $\mathrm{CO}_{2}$, pyruvate, and $\mathrm{NADPH}$, which enhance $\mathrm{CO}_{2}$ assimilation (Sui et al., 2015).

So far, the molecular mechanism of comprehensive salt responses in sweet sorghum has been largely unknown. It is necessary to draw great attention on the mechanism of salt tolerance and the functions of salt-tolerant genes/proteins in sorghum.

\section{GENOME-WIDE AND GENETIC ENGINEERING OF SWEET SORGHUM TO IMPROVE SALT TOLERANCE}

The sequencing of the whole sorghum genome was completed in 2008 (Paterson et al., 2008). To date, 820 sorghum proteinencoding sequences have been registered (http://www.gramene. org). The molecular cytogenetic maps have also been completed using multiprobe FISH cocktails technology (Islamfaridi et al., 2002). Zheng et al. (2011) carried out the genome resequencing of sweet sorghum and Chinese sorghum strains using a secondgeneration high-throughput sequencing platform. In total, 95\% of the sequences were mapped to the sorghum genome, and a large number of single-nucleotide polymorphisms were found (Zheng et al., 2011). The completion of the genome sequencing laid the foundation for in-depth study of functional genes in sweet sorghum. Many resistance-related genes, including those encoding key enzymes of some metabolic pathways, and genes important for biological productions have been characterized. Developing an efficient genetic transformation system is pivotal for molecular breeding and understanding the genetic control of plant physiology and development. It is especially necessary for the salt-tolerance breeding of sweet sorghum. Currently, the absence of an efficient sweet sorghum transformation protocol represents a major bottleneck in salt-tolerance genetic engineering (Raghuwanshi and Birch, 2010; Liu and Godwin, 2012).

\section{CONCLUSION AND PERSPECTIVES}

To survive under salt stress, plants have developed multiple salt tolerance mechanisms. Briefly, sweet sorghum improves the $\mathrm{Na}^{+}$ exclusion ability to ensure a relatively low $\mathrm{Na}^{+}$concentration in shoots. Additionally, salt-tolerant sweet sorghum can maintain a high sugar content in shoots, by protecting the assembly of photosystems, enhancing the biosynthesis of sucrose and inhibiting the degradation. However, many puzzles for understanding the sweet sorghum acclimation to salt stress remain to be elucidated, for example, the regulation of salttolerant pathways and their interactions, how to apply the theoretical research outputs to field for crop production. To address these puzzles, more advanced and in-depth studies are required. In the future, some techniques such as gene editing systems may be used to address these questions. It will promote biotechnological applications and molecular breeding of salttolerant crops, which can increase the usage of saline land and crop production.

\section{ETHICS STATEMENT}

Written informed consent was obtained from the individual(s) for the publication of any potentially identifiable images or data included in this article.

\section{AUTHOR CONTRIBUTIONS}

ZY and J-LL initiated preparation of the manuscript. NS, QX, and L-NL finalized the manuscript. All authors have read and approved the final manuscript.

\section{FUNDING}

We are grateful for financial support from the National Key R\&D Program of China (2018YFD1000700, 2018YFD1000704), the National Natural Science Research Foundation of China (31871538), Shandong Provincial Natural Science Foundation (ZR2016JL028), Major Program of Shandong Provincial Natural Science Foundation (2017C03), Shandong Province Key Research and Development Program (2019GSF107079), the Development Plan for Youth Innovation Team of Shandong Provincial (2019KJE012), Shandong Provincial Natural Science Foundation (ZR2015EM007), Royal Society (UF120411 and $\mathrm{URF} \backslash \mathrm{R} \backslash 180030$ to $\mathrm{L}-\mathrm{NL}$ ), and the UK Biotechnology and Biological Sciences Research Council (BB/R003890/1 to L-NL). 


\section{REFERENCES}

Ahmad, P., and Prasad, M. (2012). Environmental adaptations and stress tolerance of plants in the era of climate change (New York: Springer Science \& Business Media). doi: 10.1007/978-1-4614-0815-4_2

Almodares, A., and Hadi, M. R. (2009). Production of bioethanol from sweet sorghum: a review. Afr. J. Agric. Res. 4, 772-780. doi: 10.1021/jf9024163

Almodares, A., Hadi, M. R., and Dosti, B. (2007). Effects of salt stress on germination percentage and seedling growth in sweet sorghum cultivars. J. Biol. Sci. 7, 1492-1495. doi: 10.3923/jbs.2007.1492.1495

Almodares, A., Hadi, M. R., Kholdebarin, B., Samedani, B., and Kharazian, Z. A. (2014). The response of sweet sorghum cultivars to salt stress and accumulation of $\mathrm{Na}+, \mathrm{Cl}-$ and $\mathrm{K}+$ ions in relation to salinity. J. Environ. Biol. 35, 733-739. doi: 10.1246/bcsj.44.99

Antonopoulou, G., Gavala, H. N., Skiadas, I. V., Angelopoulos, K., and Lyberatos, G. (2008). Biofuels generation from sweet sorghum: fermentative hydrogen production and anaerobic digestion of the remaining biomass. Bioresource Technol. 99 (1), 110-119. doi: 10.1016/ j.biortech.2006.11.048

Blumwald, E. (2000). Sodium transport and salt tolerance in plants. Curr. Opin. In Cell Biol. 12, 431-434. doi: 10.1016/S0955-0674(00)00112-5

Buchanan, C. D., Lim, S., Salzman, R. A., Kagiampakis, I., Morishige, D. T., Weers, B. D., et al. (2005). Sorghum bicolor's transcriptome response to dehydration, high salinity and ABA. Plant Mol. Biol. 58, 699-720. doi: 10.1007/s11103-005-7876-2

Byrt, C. S., Platten, J. D., Spielmeyer, W., James, R. A., Lagudah, E. S., Dennis, E. S., et al. (2007). HKT1; 5-like cation transporters linked to Na+ exclusion loci in wheat, Nax2 and Kna1. Plant Physiol. 143, 1918-1928. doi: 10.1104/ pp.106.093476

Byrt, C. S., Xu, B., Krishnan, M., Lightfoot, D. J., Athman, A., Jacobs, A. K., et al. (2014). The Na+ transporter, TaHKT1;5-D, limits shoot Na+ accumulation in bread wheat. Plant J. Cell Mol. Biol. 80, 516-526. doi: 10.1111/tpj.12651

Cao, S., Du, X. H., Li, L. H., Liu, Y. D., Zhang, L., Pan, X., et al. (2017). Overexpression of Populus tomentosa cytosolic ascorbate peroxidase enhances abiotic stress tolerance in tobacco plants. Russian J. Plant Physiol. 64 (2), 224-234. doi: 10.1134/s1021443717020029

Carter, P. J., Nimmo, H. G., Fewson, C. A., and Wilkins, M. B. (1990). Bryophyllum fedtschenkoi protein phosphatase $2 \mathrm{~A}$ can dephosphorylate phosphoenolpyruvate carboxylase. FEBS Letters 263, 233-236. doi: 10.1016/ 0014-5793(90)81381-W

Casto, A. L., McKinley, B. A., Yu, K. M. J., Rooney, W. L., and Mullet, J. E. (2018). Sorghum stem aerenchyma formation is regulated by SbNAC_D during internode development. Plant Direct 2 (11), e00085. doi: 10.1002/pld3.85

Chai, Y. Y., Jiang, C. D., Shi, L., Shi, T. S., and Gu, W. B. (2010). Effects of exogenous spermine on sweet sorghum during germination under salinity. Biol. Plantarum 54, 145-148. doi: 10.1007/s10535-010-0023-1

Chen, M., Zhang, W. H., Lv, Z. W., Zhang, S. L., Hidema, J., Shi, F. M., et al. (2013a). Abscisic acid is involved in the response of Arabidopsis mutant sad2-1 to ultraviolet-B radiation by enhancing antioxidant enzymes. South Afr. J. Botany 85, 79-86. doi: 10.1016/j.sajb.2012.11.006

Chen, X., Zhu, W., Azam, S., Li, H., Zhu, F., Li, H., et al. (2013b). Deep sequencing analysis of the transcriptomes of peanut aerial and subterranean young pods identifies candidate genes related to early embryo abortion. Plant Biotechnol. J. 11, 115-127. doi: 10.1111/pbi.12018

Chen, L., Yuan, X., Li, J., Dong, Z., and Shao, T. (2018). Effects of applying oilextracted microalgae on the fermentation quality, feed-nutritive value and aerobic stability of ensiled sweet sorghum. J. Sci. Food Agric. 98, 4462-4470. doi: $10.1002 /$ jsfa. 8970

Chen, M., Yang, Z., Liu, J., Zhu, T., and Wang, B. (2018). Adaptation mechanism of salt excluders under saline conditions and its applications. Int. J. Mol. Sci. 19, 3668. doi: 10.3390/ijms19113668

Colebrook, E. H., Thomas, S. G., Phillips, A. L., and Hedden, P. (2014). The role of gibberellin signalling in plant responses to abiotic stress. J. Exp. Biol. 217, 6775. doi: $10.1242 /$ jeb. 089938

Cui, F., Sui, N., Duan, G., Liu, Y., Han, Y., Liu, S., et al. (2018). Identification of metabolites and transcripts involved in salt stress and recovery in peanut. Front. In Plant Sci. 9, 217. doi: 10.3389/fpls.2018.00217
Dai, L. Y., Zhang, L. J., Jiang, S. J., and Yin, K. D. (2014). Saline and alkaline stress genotypic tolerance in sweet sorghum is linked to sodium distribution. Acta Agric Scandinavica. 64, 471-481. doi: 10.1080/09064710.2014.925574

Deng, Y., Feng, Z., Yuan, F., Guo, J., Suo, S., and Wang, B. (2015). Identification and functional analysis of the autofluorescent substance in Limonium bicolor salt glands. Plant Physiol. Biochem. 97, 20-27. doi: 10.1016/j.plaphy.2015. 09.007

Ding, T. L., Song, J., Guo, J. R., Sui, N., Fan, H., Chen, M., et al. (2013). The cultivation technique for increasing the stalk sugar content of energy plant sweet sorghum in Yellow River delta. Adv Mat Res. 724, 437-442. doi: 10.4028/ www.scientific.net/AMR.724-725.437

Ding, T., Yang, Z., Wei, X., Yuan, F., Yin, S., and Wang, B. (2018). Evaluation of salt-tolerant germplasm and screening of the salt-tolerance traits of sweet sorghum in the germination stage. Funct. Plant Biol. 45, 1073-1081. doi: 10.1071/FP18009

Dionisio-Sese, M. L., and Tobita, S. (2000). Effects of salinity on sodium content and photosynthetic responses of rice seedlings differing in salt tolerance. $J$. Plant Physiol. 157, 54-58. doi: 10.1016/S0176-1617(00)80135-2

Echevaria, E., Garcia-Maurino, S. R., Soler, A., and Vidal, J. (2001). Salt stress increases the $\mathrm{Ca} 2+$-independent phosphoenolpyruvate carboxylase kinase activity in sorghum leaves. Planta 214 (2), 283-287. doi: 10.1007/ s004250100616

Evelin, H., Kapoor, R., and Giri, B. (2009). Arbuscular mycorrhizal fungi in alleviation of salt stress: a review. Ann. Botany 104, 1263-1280. doi: 10.1093/ aob/mcp251

Fan, H., Cheng, R. R., Wu, H. D., Cheng, S., Yan, J., Ding, T. L., et al. (2013). Planting sweet sorghum in Yellow River Delta: agronomy characters of different varieties and the effects of sowing time on the yield and other biological traits. Adv Mat Res. 726-731, 3-8. doi: 10.4028/www.scientific.net/ AMR.726-731.3

Feng, Z. T., Deng, Y. Q., Fan, H., Sun, Q. J., Sui, N., and Wang, B. S. (2014). Effects of $\mathrm{NaCl}$ stress on the growth and photosynthetic characteristics of Ulmus pumila L. seedlings in sand culture. Photosynthetica 52, 313-320. doi: 10.1007/ s11099-014-0032-y

Ferraris, R., and Charles-Edwards, D. A. (1986). A comparative analysis of the growth of sweet and forage sorghum crops. II. Accumulation of soluble carbohydrates and nitrogen. Aust. J. Agric. Res. 37, 513. doi: 10.1071/ar9860513

Flowers, T. J., and Colmer, T. D. (2010). Salinity tolerance in halophytes. New Phytol. 179, 945-963. doi: 10.1111/j.1469-8137.2008.02531.x

Galka, P., Santabarbara, S., Khuong, T. T. H., Degand, H., Morsomme, P., Jennings, R. C., et al. (2012). Functional analyses of the plant photosystem Ilight-harvesting complex II supercomplex reveal that light-harvesting complex II loosely bound to photosystem II is a very efficient antenna for photosystem I in state II. Plant Cell. 24, 2963-2978. doi: 10.1105/tpc.112.100339

García-Mauriño, S., Monreal, J., Alvarez, R., Vidal, J., and Echevarría, C. (2003). Characterization of salt stress-enhanced phosphoenolpyruvate carboxylase kinase activity in leaves of Sorghum vulgare: Independence from osmotic stress, involvement of ion toxicity and significance of dark phosphorylation. Planta 216 (4), 648-655. doi: 10.2307/23387685

Getachew, G., Putnam, D. H., Ben, C. M. D., and Peters, E. J. D. (2016). Potential of sorghum as an alternative to corn forage. Am. J. Plant Sci. 7 (7), 1106-1121. doi: $10.4236 /$ ajps.2016.77106

Gnansounou, E., Dauriat, A., and Wyman, C. E. (2005). Refining sweet sorghum to ethanol and sugar: economic trade-offs in the context of North China Bioresource Technol. 96, 985-1002. doi: 10.1016/j.biortech.2004.09.015

Guimaraes, C. T., Sills, G. R., and Sobral, B. W. S. (1997). Comparative mapping of Andropogoneae: Saccharum L. (sugarcane) and its relation to sorghum and maize. Proc. Natl. Acad. Sci. 94, 14261-14266. doi: 10.1073/pnas.94.26.14261

Guo, Y. H., Wang, D., Jia, W. J., Song, J., Yang, J. C., and Wang, B. S. (2012). Effects of seed vernalisation and photoperiod on flowering induction in the halophyte Thellungiella halophila. Aust. J. Botany 60 (8), 743-748. doi: 10.1071/bt12180

Guo, Y., Song, Y., Zheng, H., Zhang, Y., and Sui, N. (2018a). NADP-malate dehydrogenase of sweet sorghum improves salt tolerance of Arabidopsis thaliana. J. Agric. Food Chem. 66, 5992-6002. doi: 10.1021/acs.jafc.8b02159

Guo, Y. Y., Tian, S. S., Liu, S. S., Wang, W. Q., and Sui, N. (2018b). Energy dissipation and antioxidant enzyme system protect photosystem II of sweet sorghum under drought stress. Photosynthetica 56, 861-872. doi: 10.1007/ s11099-017-0741-0 
Ha, S., Vankova, R., Yamaguchi-Shinozaki, K., Shinozaki, K., and Tran, L. S. (2012). Cytokinins: metabolism and function in plant adaptation to environmental stresses. Trends In Plant Sci. 17, 172-179. doi: 10.1186/ s12864-015-1760-5

Han, G., Wang, M., Yuan, F., Sui, N., Song, J., and Wang, B. (2014). The CCCH zinc finger protein gene AtZFP1 improves salt resistance in Arabidopsis thaliana. Plant Mol. Biol. 86, 237-253. doi: 10.1007/s11103-014-0226-5

Hatch, M. D. (1987). C4 photosynthesis: a unique elend of modified biochemistry, anatomy and ultrastructure. Bba Reviews Bioenergetics. 895, 81-106. doi: 10.1016/S0304-4173(87)80009-5

Heidari, M. (2009). Antioxidant activity and osmolyte concentration of sorghum (Sorghum bicolor) and wheat (Triticum aestivum) genotypes under salinity stress. Asian J. Plant Sci. 8 (3), 240-244. doi: 10.1118/1.598892

Hoffmann-Thoma, G., Hinkel, K., Nicolay, P., and Willenbrink, J. (2010). Sucrose accumulation in sweet sorghum stem internodes in relation to growth. Physiol Plantarum 97, 277-284. doi: 10.1034/j.1399-3054.1996.970210.x

IEA. (2019). Data from: Key World Energy Statistics 2018. https://webstore.iea.org/ key-world-energy-statistics-2018

Islamfaridi, M. N., Childs, K. L., Klein, P. E., Hodnett, G., Menz, M. A., Klein, R. R., et al. (2002). A molecular cytogenetic map of sorghum chromosome 1. Fluorescence in situ hybridization analysis with mapped bacterial artificial chromosomes. Genetics 161, 345. doi: 10.1023/A:1016080316076

Javid, M. G., Sorooshzadeh, A., Moradi, F., Sanavy, S. A. M. M., and Allahdadi, I. (2011). The role of phytohormones in alleviating salt stress in crop plants. Aust. J. Crop Sci. 32, 726-734. doi: 10.1163/156853811X610320

Jiao, L., Wang, L., Zhou, Q., and Huang, X. (2017). Stomatal and non-stomatal factors regulated the photosynthesis of soybean seedlings in the present of exogenous bisphenol A. Ecotoxicol Environ. Saf. 145, 150-160. doi: 10.1016/ j.ecoenv.2017.07.028

Jogeswar, G., Pallela, R., Jakka, N. M., Reddy, P. S., Rao, J. V., and Sreenivasulu, N. (2006). Antioxidative response in different sorghum species under short-term salinity stress. Acta Physiol Plantarum 28, 465-475. doi: 10.1007/bf02706630

Kühn, C., and Grof, C. P. (2010). Sucrose transporters of higher plants. Curr. Opin. In Plant Biol. 13, 287-297. doi: 10.1016/j.pbi.2010.02.001

Kazuo, N., Yasunari, F., Norihito, K., Takeshi, K., Taishi, U., Satoshi, K., et al. (2009). Three Arabidopsis SnRK2 protein kinases, SRK2D/SnRK2.2, SRK2E/ SnRK2.6/OST1 and SRK2I/SnRK2.3, involved in ABA signaling are essential for the control of seed development and dormancy. Plant Cell Physiol. 50, 1345-1363. doi: 10.1093/pcp/pcp083

Kong, X. Q., Gao, X. H., Sun, W., An, J., Zhao, Y. X., and Zhang, H. (2011). Cloning and functional characterization of a cation-chloride cotransporter gene OsCCC1. Plant Mol. Biol. 75 (6), 567-578. doi: 10.1007/s11103-011-9744-6

Kong, X. Q., Wang, T., Li, W. J., Tang, W., Zhang, D. M., and Dong, H. Z. (2016). Exogenous nitric oxide delays salt-induced leaf senescence in cotton (Gossypium hirsutum L.). Acta Physiol Plantarum 38 (3), 61. doi: 10.1007/ s11738-016-2079-9

Krishnamurthy, P., Ranathunge, K., Franke, R., Prakash, H. S., Schreiber, L., and Mathew, M. K. (2009). The role of root apoplastic transport barriers in salt tolerance of rice (Oryza sativa L.). Planta 230, 119-134. doi: 10.2307/23390598

Krishnamurthy, P., Ranathunge, K., Nayak, S., Schreiber, L., and Mathew, M. K. (2011). Root apoplastic barriers block $\mathrm{Na}+$ transport to shoots in rice (Oryza sativa L.). J. Exp. Botany 62, 4215-4228. doi: 10.1093/jxb/err135

Lacerda, C. F. D, Cambraia, J., Olivia, M. A., Ruiz, H. A., and Prisco, J. T. (2003). Solute accumulation and distribution during shoot and leaf development in two sorghum genotypes under salt stress. Environ. Exp. Botany. 49 (2), 107120. doi: 10.1016/S0098-8472(02)00064-3

Landi, S., Hausman, J. F., Guerriero, G., and Esposito, S. (2017). Poaceae vs. abiotic stress: focus on drought and salt stress, recent insights and perspectives. Front. In Plant Sci. 8, 1214. doi: 10.3389/fpls.2017.01214

Leng, B. Y., Yuan, F., Dong, X. X., Wang, J., and Wang, B. S. (2018). Distribution pattern and salt excretion rate of salt glands in two recretohalophyte species of Limonium (Plumbaginaceae). South Afr. J. Botany 115, 74-80. doi: 10.1016/ j.sajb.2018.01.002

Li, W., Shinjiro, Y., Ajmal, K. M., Ping, A., Liu, X., and Tran, L. S. P. (2015). Roles of gibberellins and abscisic acid in regulating germination of Suaeda salsa dimorphic seeds under salt stress. Front. In Plant Sci. 6, 1235. doi: 10.3389/ fpls.2015.01235
Liu, G., and Godwin, I. D. (2012). Highly efficient sorghum transformation. Plant Cell Rep. 31, 999-1007. doi: 10.1007/s00299-011-1218-4

Liu, S., Cheng, Y., Zhang, X., Guan, Q., Nishiuchi, S., Hase, K., et al. (2007). Expression of an NADP-malic enzyme gene in rice (Oryza sativa. L) is induced by environmental stresses; over-expression of the gene in Arabidopsis confers salt and osmotic stress tolerance. Plant Mol. Biol. 64 (1-2), 49-58. doi: 10.1007/ s11103-007-9133-3

Liu, L. N. (2016). Distribution and dynamics of electron transport complexes in cyanobacterial thylakoid membranes. Biochim. Biophys. Acta (BBA) Bioenergetics 1857, 256-265. doi: 10.101 6/j.bbabio.2015.11.010

Lunn, J. E., and Macrae, E. (2003). New complexities in the synthesis of sucrose. Curr. Opin. In Plant Biol. 6, 208-214. doi: 10.1016/S1369-5266(03)00033-5

Møller, I. M. (2001). Plant mitochondria and oxidative stress: electron transport, NADPH turnover, and metabolism of reactive oxygen species. Annu. Rev. Plant Biol. 52 (1), 561-591. doi: 10.1146/annurev.arplant.52.1.561

Ma, Q., Yue, L. J., Zhang, J. L., Wu, G. Q., Bao, A. K., and Wang, S. M. (2012). Sodium chloride improves photosynthesis and water status in the succulent xerophyte Zygophyllum xanthoxylum. Tree Physiol. 32, 4-13. doi: 10.1093/ treephys/tpr098

Mahajan, S., and Tuteja, N. (2005). Cold, salinity and drought stresses: an overview. Arch. Biochem. Biophysics 444, 139-158. doi: 10.1016/j.abb.2005.10.018

Mccormick, A. J., Cramer, M. D., and Watt, D. A. (2010). Sink strength regulates photosynthesis in sugarcane. New Phytol. 171 (4), 759-770. doi: 10.1111/ j.1469-8137.2006.01785.x

Mittler, R. (2002). Oxidative stress, antioxidants and stress tolerance. Trends In Plant Sci. 7, 405-410. doi: 10.1016/S1360-1385(02)02312-9

Monreal, J. A., Feria, A. B., Vinardell, J. M., Vidal, J., Echevarría, C., and GarcíaMauriño, S. (2007). ABA modulates the degradation of phospho enol pyruvate carboxylase kinase in sorghum leaves. FEBS Letters 581 (18), 3468-3472. doi: 10.1016/j.febslet.2007.06.055

Munns, R. (1993). Physiological processes limiting plant growth in saline soils: some dogmas and hypotheses. Plant Cell Environ. 16 (1), 15-24. doi: 10.1111/ j.1365-3040.1993.tb00840.x

Nakashima, K., and Yamaguchishinozaki, K. (2013). ABA signaling in stressresponse and seed development. Plant Cell Rep. 32, 959-970. doi: 10.1007/ s00299-013-1418-1

Netondo, G. W., Onyango, J. C., and Beck, E. (2004). Sorghum and salinity: II. Gas exchange and chlorophyll fluorescence of sorghum under salt stress. Crop Sci. 44, 806-811. doi: 10.2135/cropsci2004.8060

Ng, L. M., Melcher, K., Teh, B. T., and Xu, H. E. (2014.). Abscisic acid perception and signaling: structural mechanisms and applications. Acta Pharmacol. Sinica. 35, 567-584. doi: 10.1038/aps.2014.5

Ngara, R., Ndimba, R., Borch-Jensen, J., Jensen, O. N., and Ndimba, B. (2012). Identification and profiling of salinity stress-responsive proteins in Sorghum bicolor seedlings. J. Proteomics. 75, 4139-4150. doi: 10.1016/j.jprot.2012.05.038

Oliveira, A. B. D., Alencar, N. L. M., Prisco, J. T., and Gomes-Filho, E. (2011). Accumulation of organic and inorganic solutes in $\mathrm{NaCl}$-stressed sorghum seedlings from aged and primed seeds. Scientia Agricola. 68, 632-637. doi: 10.1590/S0103-90162011000600004

Pang, C. H., Li, K., and Wang, B. (2011). Overexpression of SsCHLAPXs confers protection against oxidative stress induced by high light in transgenic Arabidopsis thaliana. Physiol plantarum. 143 (4), 355-366. doi: 10.1111/ j.1399-3054.2011.01515.x

Panuccio, M. R., Jacobsen, S. E., Akhtar, S. S., and Muscolo, A. (2014). Effect of saline water on seed germination and early seedling growth of the halophyte quinoa. AoB Plants 6, plu047. doi: 10.1093/aobpla/plu047

Patanè, C., Cavallaro, V., and Cosentino, S. L. (2009). Germination and radicle growth in unprimed and primed seeds of sweet sorghum as affected by reduced water potential in $\mathrm{NaCl}$ at different temperatures. Industrial Crops Product. 30, 1-8. doi: 10.1016/j.indcrop.2008.12.005

Patanè, C., Saita, A., and Sortino, O. (2013). Comparative effects of salt and water stress on seed germination and early embryo growth in two cultivars of sweet sorghum. J. Agron. Crop Sci. 199, 30-37. doi: 10.1111/j.1439-037X.2012.00531.x

Paterson, A. H., Bowers, J. E., and Feltus, F. A. (2008). "Genomics of sorghum, a semi-arid cereal and emerging model for tropical grass genomics," in Genomics of Tropical Crop Plants. Eds. P. H. Moore and R. Ming (New York: Springer), 469-482. doi: 10.1007/978-0-387-71219-2_20 
Patra, A. K., and Saxena, J. (2011). Exploitation of dietary tannins to improve rumen metabolism and ruminant nutrition. J. Sci. Food Agric. 91 (1), 24. doi: $10.1002 /$ jsfa. 4152

Pignocchi, C., and Foyer, C. H. (2003). Apoplastic ascorbate metabolism and its role in the regulation of cell signalling. Curr. Opin. In Plant Biol. 6, 379-389. doi: 10.1016/S1369-5266(03)00069-4

Qazi, H. A., Paranjpe, S., and Bhargava, S. (2012). Stem sugar accumulation in sweet sorghum-activity and expression of sucrose metabolizing enzymes and sucrose transporters. J. Plant Physiol. 169, 605-613. doi: 10.1016/ j.jplph.2012.01.005

Rae, A. L., Perroux, J. M., and Grof, C. P. L. (2005). Sucrose partitioning between vascular bundles and storage parenchyma in the sugarcane stem: a potential role for the ShSUT1 sucrose transporter. Planta 220, 817-825. doi: 10.2307/ 23388789

Raghuwanshi, A., and Birch, R. G. (2010). Genetic transformation of sweet sorghum. Plant Cell Rep. 29, 997-1005. doi: 10.1007/s00299-010-0885-x

Rao, P. S., Kumar, C. G., and Reddy, B. V. S. (2013). "Sweet sorghum: from theory to practice," in Characterization of improved sweet sorghum cultivars. Springer Briefs in Agriculture. Eds. P. Rao and C. Kumar (India: Springer). doi: 10.1007/ 978-81-322-0783-2_1

Reinders, A., Sivitz, A. B., Hsi, A., Grof, C. P., Perroux, J. M., and Ward, J. M. (2010). Sugarcane ShSUT1: analysis of sucrose transport activity and inhibition by sucralose. Plant Cell Environ. 29, 1871-1880. doi: 10.1111/j.13653040.2006.01563.x

Ryu, H., and Cho, Y.-G. (2015). Plant hormones in salt stress tolerance. J. Plant Biol. 58, 147-155. doi: 10.1007/s12374-015-0103-z

Sánchez-Duarte, J. I., Kalscheur, K. F., García, A. D., and Contreras-Govea, F. E. (2018). Short communication: Meta-analysis of dairy cows fed conventional sorghum or corn silages compared with brown midrib sorghum silage. J. Dairy Sci. 102 , 1-7. doi: $10.3168 /$ jds.2018-14552

Sah, S. K., Reddy, K. R., and Li, J. (2016). Abscisic acid and abiotic stress tolerance in crop plants. Front. In Plant Sci. 7, 571. doi: 10.3389/fpls.2016.00571

Schäfer, W. E., Rohwer, J. M., and Botha, F. C. (2005). Partial purification and characterisation of sucrose synthase in sugarcane. J. Plant Physiol. 162, 11-20. doi: $10.1016 /$ j.jplph.2004.04.010

Scofield, G. N., Hirose, T., Aoki, N., and Furbank, R. T. (2007). Involvement of the sucrose transporter, OsSUT1, in the long-distance pathway for assimilate transport in rice. J. Exp. Botany 58, 3155-3169. doi: 10.1093/jxb/erm153

Shao, Q., Han, N., Ding, T., Zhou, F., and Wang, B. (2014). SsHKT1; 1 is a potassium transporter of the $\mathrm{C} 3$ halophyte Suaeda salsa that is involved in salt tolerance. Funct. Plant Biol. 41 (8), 790-802. doi: 10.1071/FP13265

Slewinski, T. L. M., and Robert and Braun, D. M. (2010). Sucrose transporter1 functions in phloem loading in maize leaves. J. Exp. Botany 60, 881-892. doi: $10.1093 / \mathrm{jxb} / \mathrm{ern} 335$

Song, J., and Wang, B. (2015). Using euhalophytes to understand salt tolerance and to develop saline agriculture: Suaeda salsa as a promising model. Ann. Bot. 115, 541. doi: 10.1093/aob/mcu194

Song, J., Zhou, J., Zhao, W., Xu, H., Wang, F., Xu, Y., et al. (2016). Effects of salinity and nitrate on production and germination of dimorphic seeds applied both through the mother plant and exogenously during germination in Suaeda salsa. Plant Species Biol. 31, 19-28. doi: 10.1111/1442-1984.12071

Sudhir, P., and Murthy, S. D. S. (2004). Effects of salt stress on basic processes of photosynthesis. Photosynthetica 42, 481-486. doi: 10.1007/s11099-005-0001-6

Sui, N., and Han, G. (2014). Salt-induced photoinhibition of PSII is alleviated in halophyte Thellungiella halophila by increases of unsaturated fatty acids in membrane lipids. Acta Physiol Plantarum 36, 983-992. doi: 10.1007/s11738013-1477-5

Sui, N., Li, M., Li, K., Song, J., and Wang, B. S. (2010). Increase in unsaturated fatty acids in membrane lipids of Suaeda salsa L. enhances protection of photosystem II under high salinity. Photosynthetica 48, 623-629. doi: 10.1007/s11099-010-0080-x

Sui, N., Yang, Z., Liu, M., and Wang, B. (2015). Identification and transcriptomic profiling of genes involved in increasing sugar content during salt stress in sweet sorghum leaves. BMC Genomics 16, 534. doi: 10.3389/fpls.2018.00007
Sui, N., Wang, Y., Liu, S., Yang, Z., Wang, F., and Wan, S. (2018). Transcriptomic and physiological evidence for the relationship between unsaturated fatty acid and salt stress in peanut. Front. In Plant Sci. 9, 7.

Sun, S.-B., Shen, Q.-R., Wan, J.-M., and Liu, Z.-P. (2003). Induced expression of the gene for NADP-malic enzyme in leaves of Aloe vera L. under salt stress. Acta Biochim. Biophys. Sinica. 35 (5), 423-429. doi: 10.1016/S0022-2836(03) 00269-9

Sun, L., Wang, C., Zhou, Y. F., Ruan, Y. Y., Gong, X., and Zhang, J. (2016). Inhibition of sbabi5 expression in roots by ultra-high endogenous aba accumulation results in sorghum sensitivity to salt stress. Int. J. Agric. Biol. 18, 146-154. doi: 10.17957/IJAB/15.0079

Tan, H. Y., Sieo, C. C., Abdullah, N., Liang, J. B., Huang, X. D., and Ho, Y. W. (2011). Effects of condensed tannins from Leucaena on methane production, rumen fermentation and populations of methanogens and protozoa in vitro. Anim. Feed Sci. Technol. 169 (3-4), 185-193. doi: 10.1016/j.anifeedsci. 2011.07.004

Tarpley, L., and Vietor, D. M. (2007). Compartmentation of sucrose during radial transfer in mature sorghum culm. BMC Plant Biol. 7, 33. doi: 10.1186/14712229-7-33

Turgeon, R. (1989). The Sink-Source Transition in Leaves. Annu. Rev. Plant Physiol. Plant Mol. Biol. 40, 119-138. doi: 10.1146/annurev.pp.40.060189.001003

Vasilakoglou, I., Dhima, K., Karagiannidis, N., and Gatsis, T. (2011). Sweet sorghum productivity for biofuels under increased soil salinity and reduced irrigation. Field Crops Res. 120, 38-46. doi: 10.1016/j.fcr.2010.08.011

Vidal, J., and Chollet, R. (1997). Regulatory phosphorylation of C4 PEP carboxylase. Plant Physiol. 2 (6), 230-237. doi: 10.1016/S1360-1385(97) 89548-9

Wang, R., Chen, S., Deng, L., Fritz, E., Hüttermann, A., and Polle, A. (2007). Leaf photosynthesis, fluorescence response to salinity and the relevance to chloroplast salt compartmentation and anti-oxidative stress in two poplars. Trees Struct. Funct. 21 (5), 581-591. doi: 10.1007/s00468-007-0154-y

Wang, T. T., Ren, Z. J., Liu, Z. Q., Feng, X., Guo, R. Q., Li, B. G., et al. (2014). SbHKT1;4, a member of the high-affinity potassium transporter gene family from Sorghum bicolor, functions to maintain optimal $\mathrm{Na}+/ \mathrm{K}+$ balance under $\mathrm{Na}+$ stress. J. Integr. Plant Biol. 56, 315-332. doi: 10.1111/jipb.12144

Whitney, S. M., Houtz, R. L., and Alonso, H. (2011). Advancing our understanding and capacity to engineer nature's $\mathrm{CO} 2$-sequestering enzyme, Rubisco. Plant Physiol. 155 (1), 27-35. doi: 10.1104/pp.110.164814

Wydrzynski, T. J. (2008). Water splitting by photosystem II-where do we go from here? Photosynthesis Res. 98, 43-51. doi: 10.1007/s11120-008-9391-1

Xie, Q., and Xu, Z. H. (2019). Sustainable sgriculture: from sweet sorghum planting and ensiling to ruminant feeding. Mol. Plant 12, 603-606. doi: 10.1016/j.molp.2019.04.001

Xin, S., Yu, G., Sun, L., Qiang, X., Xu, N., and Cheng, X. (2014). Expression of tomato SITIP2;2 enhances the tolerance to salt stress in the transgenic Arabidopsis and interacts with target proteins. J. Plant Res. 127 (6), 695-708. doi: 10.1007/s10265-014-0658-7

Xue, X., Zhang, Q., and Wu, J. (2013). Research of reactive oxygen species in plants and its application on stress tolerance. Biotechnol. Bulletin. 36, 6-11. doi: 10.13560/j.cnki.biotech.bull.1985.2013.10.033

Yang, Z., Wang, Y., Wei, X., Zhao, X., Wang, B., and Sui, N. (2017). Transcription profiles of genes related to hormonal regulations under salt stress in sweet sorghum. Plant Mol. Biol. Rep. 35, 1-14. doi: 10.1007/s11105-017-1047-x

Yang, Z., Zheng, H., Wei, X., Song, J., Wang, B., and Sui, N. (2018). Transcriptome analysis of sweet Sorghum inbred lines differing in salt tolerance provides novel insights into salt exclusion by roots. Plant Soil. 430, 423-439. doi: 10.1007/ s11104-018-3736-0

Yuan, F., Leng, B., and Wang, B. (2016a). Progress in studying salt secretion from the salt glands in recretohalophytes: how do plants secrete Salt? Front. In Plant Sci. 7, 997. doi: 10.3389/fpls.2016.00977

Yuan, F., Lyu, M. J. A., Leng, B. Y., Zhu, X. G., and Wang, B. S. (2016b). The transcriptome of NaCl-treated Limonium bicolor leaves reveals the genes controlling salt secretion of salt gland. Plant Mol. Biol. 91, 241-256. doi: 10.1007/s11103-016-0460-0 
Zeng, Y., Shen, J., Li, B., and Jiang, L. (2018). Hormone modulates protein dynamics to regulate plant growth. Proc. Natl. Acad. Sci. 115, 3521-3523. doi: 10.1073/pnas.1802175115

Zheng, L. Y., Guo, X. S., He, B., Sun, L. J., Peng, Y., Dong, S. S., et al. (2011). Genome-wide patterns of genetic variation in sweet and grain sorghum (Sorghum bicolor). Genome Biol. 12, R114. doi: 10.1186/gb-2011-12-11-r114

Zhu, J. K. (2001). Plant salt tolerance. Trends In Plant Sci. 6 (2), 66-71. doi: 10.1016/S1360-1385(00)01838-0

Zwack, P. J., and Rashotte, A. M. (2015). Interactions between cytokinin signalling and abiotic stress responses. J. Exp. Botany 66, 4863. doi: 10.1093/jxb/erv172
Conflict of Interest: The authors declare that the research was conducted in the absence of any commercial or financial relationships that could be construed as a potential conflict of interest.

Copyright (c) 2020 Yang, Li, Liu, Xie and Sui. This is an open-access article distributed under the terms of the Creative Commons Attribution License (CC BY). The use, distribution or reproduction in other forums is permitted, provided the original author (s) and the copyright owner(s) are credited and that the original publication in this journal is cited, in accordance with accepted academic practice. No use, distribution or reproduction is permitted which does not comply with these terms. 